et al. (20) and Lemkin and Farquhar (2) have demonstrated that the ${ }^{35}$ sulfate in rat GBM is incorporated into glycosaminoglycans and glycopeptides. The majority of the ${ }^{35}$ sulfate is found in heparan sulfate. The glycopeptides have not been defined, but they may represent entactin, a recently described sulfated glycoprotein associated with basement membranes (21). The nephrotic PBMC may release a factor that induces increased catabolism of the GBM sulfated compounds, with subsequently increased synthesis as cells react to the increased catabolism. Conversely, the supernatant factor could directly stimulate the synthesis of proteoglycans and/or glycoproteins. Thus, the PBMC could be compensating for an already increased catabolism of sulfated compounds in the GBM. Because the sulfated compounds play a role in glomerular permeability, the answers to these questions will give us insight into the biological significance of this supernatant factor and possibly the pathogenesis of IMLNS.

\section{REFERENCES}

1. Carrie BJ. Salyer WR. Myers BD 1981 Minimal change nephropathy: an electrochemical disorder of the glomerular membrane. Am J Med 70:262268

2. Lemkin MC, Farquhar MG 1981 Sulfated and nonsulfated glycosaminoglycans and glycopeptides are synthesized by kidney "in vivo" and incorporated into glomerular basement membrane. Proc Nat Acad Sci USA 78:1726-1739

3. Kanwar YS, Farquhar MG 1983 Immune Mechanisms in Renal Disease. Plenum Press, New York, pp 1-35

4. Rosenweig LJ, Kanwar YS 1982 Removal of sulfated (heparan sulfate) or non sulfated (hyaluronic acid) glycosaminoglycans results in increased permeability of the glomerular basement membrane to ${ }^{125} \mathrm{I}$ bovine serum albumin. Lab Invest 47:177-184

5. Garin EG, Boggs KP 1985 Effect of peripheral blood mononuclear cells from patients with from nephrotic syndrome on uptake of ${ }^{35}$ sulfate by glomerular basement membrane. Int $J$ Pediatr Nephrol (in press)

6. Churg J. Habib R. Whitc RHR 1970 Pathology of the nephrotic syndrome in children: a report for the International Study of Kidney Discase in Children.
Lancet 1:1299-1302

7. Boyum A 1968 Isolation of mononuclear cells and granulocytes from human blood. Scand J Clin Lab Invest 21(suppl)97:77-89

8. Fong JCS, Drummond KN 1968 Method for preparation of glomeruli for metabolic studies. J Lab Clin Med 71:1034-1040

9. Meezan E, Hjelle JT, Brendel K, Carlson EC 1975 A simple, versatile, nondisruptive method for the isolation of morphologically and chemically pure basement membrane from several tissues. Life Sci 17:1721-1732

10. Goodyer PR, Kaplan BS 1984 In vitro incorporation of ${ }^{35} \mathrm{SO}_{4}$ into glomerular basement membrane is reduced in puromycin aminonucleoside nephrosis. Kidney Int 25:211(abstr)

11. Murata K, Horiuchi Y 1978 Age-dependent distribution of acidic glycosaminoglycans in human kidney tissue. Nephron 20:111-118

12. Mcleod T, McKinney C, Zilleruelo G, Sandberg D, Strauss J 1981 Inhibition of lymphocyte blastogenesis by serum B lipoprotein from minimal change nephrotic syndrome (MLNS) patients. Pediatr Res 15:697(abstr)

13. Garin EG, Barratt TM 1982 Effect of indomethacin on lymphocyte response to mitogens in puromycin aminonucleoside nephrosis in the rat. Clin Exp Immunol 49:639-644

14. Gherardi E, Rota E, Calandra S, Genova R, Tamborino A 1977 Relationship among the concentrations of serum lipoproteins and changes in their chemical composition in patients with untreated nephrotic syndrome. Eur J Clin Invest $7: 563-570$

15. Garin EH, Sausville PJ, Richard GA 1983 Plasma prostaglandin $E_{2}$ concentration in nephrotic syndrome. J Pediatr 103:253-256

16. Mallick NP 1977 The pathogenesis of minimal change nephropathy. Clin Nephrol 7:87-95

17. Lagrue G, Xheneumont S, Branellec A, Hirbec G, Weil B 1975 A vascular permeability factor elaborated from lymphocytes. I. Demonstration in patients with nephrotic syndrome. Biomedicine 23:37-40

18. Trompeter RS, Barratt TM, Layward L 1978 Vascular permeability factor and nephrotic syndrome. Lancet 2:900

19. Sobel A, Heslan JM, Branellec A, Lagrue G 1981 Vascular permeability factor produced by lymphocytes of patients with nephrotic syndrome. Adv Nephrol 10:315-332

20. Brown DM, Klein DJ, Michael AF, Oegema TR $1982{ }^{35}$ S-glycosaminoglycan and ${ }^{35} \mathrm{~S}$-glycopeptide metabolism by diabetic glomeruli and aorta. Diabetes $31: 418-425$

21. Carlin B, Jaffe R, Bender B, Chung AE 1981 Entactin, a novel basal laminaassociated sulfated glycoprotein. J Biol Chem 256:5209-5214

\title{
Metabolic Quotients of the Gravid Uterus of the Chronically Catheterized Guinea Pig
}

\author{
STEVEN M. BLOCK, JOHN W. SPARKS, ROBERT L. JOHNSON, AND \\ FREDERICK C. BATTAGLIA \\ Division of Perinatal Medicine, Departments of Pediatrics, Obstetrics-Gynecology, and Physiology, University of \\ Colorado School of Medicine, Denver, Colorado 80262
}

\begin{abstract}
The uptake of substrates by the pregnant uterus defines the "diet" of the uterus and conceptus. In order to determine the uterine substrate uptake, catheters were placed in the femoral artery and uterine veins of guinea pigs at 40-49 days gestation. After at least 2 days recovery from perioperative stress, systemic arterial and uterine venous concentrations of oxygen, glucose, lactate, acetoacetate, $\beta$-hydroxybutyrate, acetate, and free fatty
\end{abstract}

Received November 7, 1983, accepted March 26, 1985.

Address for reprints Frederick C. Battaglia, M.D., Chairman, Department of Pediatrics, C-218. University of Colorado School of Medicine, 4200 East Ninth Avenue, Denver, CO 80262.

Supported by NIH Program Grant HD 00781 and NIH Project Grant HD 01806 . S.M.B. and R.L.J. supported by NIH Training Grant HD 07186. acids were measured and metabolic quotients were calculated. The glucose $/ \mathrm{O}_{2}$ quotient was $1.22 \pm 0.07$ (mean \pm $\mathrm{SEM})$, the lactate $/ \mathrm{O}_{2}$ quotient was $-0.40 \pm 0.09$, the acetoacetate $/ \mathrm{O}_{2}$ quotient was $0.03 \pm 0.02$, the $\beta$-hydroxybutyrate $/ \mathrm{O}_{2}$ quotient was $0.01 \pm 0.006$, the acetate $/ \mathrm{O}_{2}$ quotient was $0.03 \pm 0.01$, and the free fatty acid $/ \mathrm{O}_{2}$ quotient was $0.24 \pm 0.21$. Among the substrates measured, glucose appears to be the major metabolic fuel of the pregnant guinea pig uterus, but does not account for all of the oxygen consumed by the uterus if adjusted for lactate production, since lactate is produced within the gravid uterus in large quantities. Acetoacetate and $\beta$-hydroxybutyrate are utilized in negligible amounts. (Pediatr Res 19: 840-845, 1985) 


\begin{abstract}
AV, arteriovenous
PVI, polyvinyl catheter

FFA, free fatty acids
\end{abstract}

Abbreviations

The uptake of oxygen and of metabolic substrates by the pregnant uterus is of great interest in mammalian reproductive biology since it defines the "diet" of the conceptus and represents a major portion of the metabolic demand imposed on the mother by pregnancy. The uterine uptakes of oxygen and of substrates have been measured in sheep (1-4) and in the pregnant cow (5). Both of these large, ruminant mammals have an epitheliochorial placenta and both produce a fetus which is low in fat and small relative to maternal size. While data measuring uterine substrate uptakes are not available for small, unstressed, chronically catheterized animals, such data are of considerable interest, since small animals exhibit a considerably different biology of gestation. The combined weights of the guinea pig fetuses at term represent $40-60 \%$ of the maternal prepregnant weight, compared to the human $(5 \%)$ and the sheep $(7 \%)(6-8)$. The guinea pig placenta is hemochorial and labyrinthine. This species produces a fetus which at term (67 days) is $11-12 \%$ fat, more similar to the human $(16 \%)$ than the sheep $(2 \%)(6-8)$. For all these reasons, unstressed measurements of uterine substrate uptake in the guinea pig are of particular interest in understanding the comparative biology of gestation.

Recently, methods for studying the arterial and peripheral venous circulations of the conscious, pregnant guinea pig under chronic steady state conditions have been developed. The maternal arterial substrate concentrations (9), cardiac output and blood flow (10, 11; Myers S, Sparks JW, Makowski EL, Meschia G, Battaglia FC, personal communication), and glucose turnover rate and clearance (12) have been studied in our laboratory using these techniques. The present study presents a method for chronic catheterization of the uterine venous circulation, and its application to measuring AV differences of metabolic substrates and oxygen across the pregnant uterus under similar chronic steady state conditions in the conscious animal. Metabolic quotients are presented to quantitate net utilization of these substrates relative to oxygen uptake.

\section{MATERIALS AND METHODS}

Animals. Thirteen Hartley strain guinea pigs at approximately 40 days gestation were anesthetized with ketamine $(60 \mathrm{mg}$ intramuscular) and xylazine (4 mg intramuscular) (9). PVI (PVI Bolabs, Lake Havasu City, AZ) were placed in the left femoral artery and carotid artery and advanced into the descending aorta. Isoproterenol $(1.5 \mu \mathrm{g} / \mathrm{min}$ in physiologic saline $)$ was then infused into the femoral arterial catheter in order to preserve heart rate, cardiac output, and uterine blood flow during anesthesia and surgery and to permit full recovery metabolically within $48 \mathrm{hr}$ (Myers S, Sparks JW, Makowski EL, Meschia G, Battaglia FC, personal communication).

A midline abdominal incision was made and a pregnant horn of the uterus was gently delivered. The fetus closest to the ovarian end of the horn was identified and one of the veins draining the placenta along the broad ligament into the main uterine vein was isolated (Fig. 1). This vein was ligated distally, and, under an operating microscope, a PVI was inserted into the vein and advanced into the arcade formed by the main uterine vein, which lies buried in the fat of the broad ligament. The catheter was then secured with ligatures and tissue adhesive (Eastman Kodak, no. 910 , Rochester, NY). During the procedure, the uterus was kept moist with warm, sterile, physiologic saline solution. The uterus was then returned to the abdominal cavity, and the peritoneum and muscle were closed with a single continuous silk

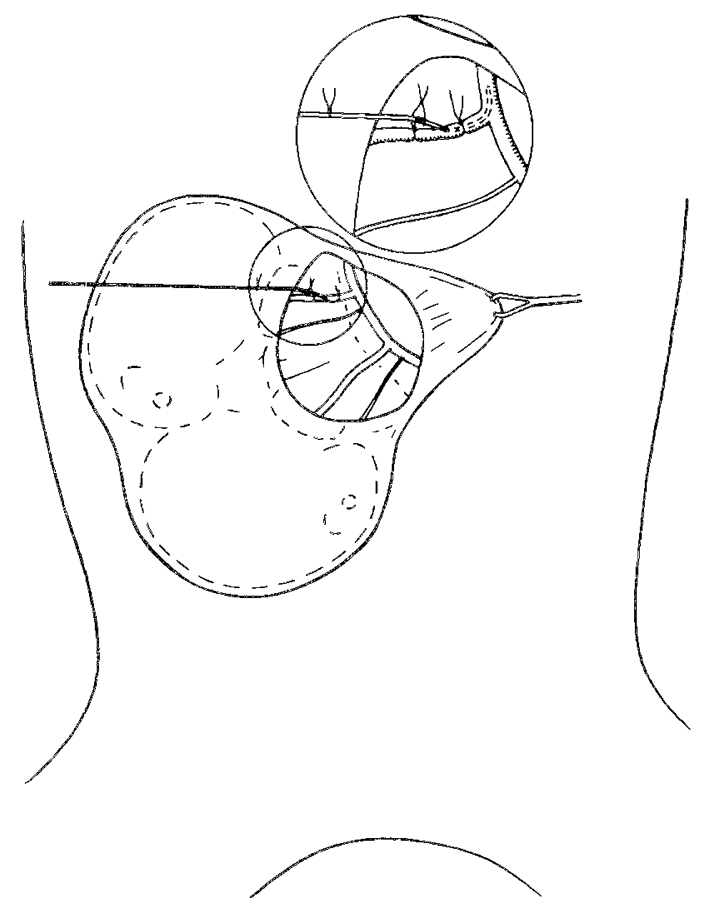

Fig. 1. Placement of the uterine venous catheter in the guinea pig. The left horn of the uterus is exposed and retracted to the right of the animal. $A$, (PVI) catheter; $B$, main uterine vein; $C$, placentas; and, $D$, fetuses.

suture. Both catheters were buried subcutaneously to emerge between the scapulae, where they were secured in a plastic cap, as described by Sparks et al. (9). The abdominal, neck, and femoral incisions were closed with a monofilament polypropylene suture (Prolene). Postoperatively, the animals were infused with physiologic saline and with glucose at approximately $8 \mathrm{mg} /$ $\mathrm{kg} / \mathrm{min}$ for about $18 \mathrm{hr}$ until they were ambulatory and had begun feeding. Catheters were flushed daily with $0.05 \mathrm{ml}$ of $0.9 \%$ $\mathrm{NaCl}$ containing $200 \mathrm{U} / \mathrm{ml}$ of heparin. Using these modifications, arterial substrate concentrations recovered more quickly than previously reported (9), achieving steady state values within $48 \mathrm{hr}$ after surgery (Myers S, Sparks JW, Makowski EL, Meschia $\mathrm{G}$, Battaglia FC, personal communication).

Pre- and postoperatively, the animals were fed ad libitum a vitamin $\mathrm{C}$-enriched, solid guinea pig diet. The animals were studied at least $48 \mathrm{hr}$ after surgery. Arterial substrate concentrations were comparable to those found by Sparks et al. (9), and food intake had returned to the normal range for gestational age. Food intake among animals ranged from $25-51 \mathrm{~g} /$ day on the day of study.

Ten additional animals were prepared acutely with femoral arterial catheters as previously described (9). The abdomen was opened and the uterus delivered. Catheters (PVI) were placed into the common uterine vein, and paired samples were withdrawn for analysis of oxygen content and glucose and lactate concentration.

Study protocol. After $48 \mathrm{hr}$ recovery, four sets of samples were drawn from the chronically prepared animals over approximately $1 \mathrm{hr}$. Each set consisted of blood samples withdrawn simultaneously from the arterial and venous catheters. Each set was analyzed in triplicate for blood concentrations of oxygen, glucose, acetoacetate, $\beta$-hydroxybutyrate, acetate, and lactate determinations. Catheters were flushed with heparinized saline between sets. The four sets of AV differences were used to calculate a mean AV difference, which was used for calculation of a single metabolic quotient for that day. A separate group of animals was studied for FFA and oxygen. In these latter animals, catheters were flushed with heparin-free saline, and sufficient time was 
permitted to clear any heparin originally in the catheter, so that FFA levels would not be elevated. Preliminary observations in our laboratory have shown that $10 \mathrm{~min}$ is sufficient time to wait for FFA levels to return to control values after flushing the heparin in the catheter dead space (approximately $10 \mathrm{U} / \mathrm{kg}$ ). The animals were transfused isovolumetrically with compatible guinea pig blood immediately after the last sample withdrawal in the study.

Each animal was restudied the next day, if the catheters remained patent. During the study, the animals were allowed to move freely about their cages with free access to food and water. On completion of the second study, each animal was sacrificed in order to determine the weights of the uterus, placentae, and fetuses, both in the catheterized and noncatheterized uterine horns, and to verify the position of the catheters.

Gestational age was obtained from the date of breeding supplied by the breeders and confirmed using published growth charts of the fetal guinea pig $(6,13,14)$.

Analytical methods. Oxygen content was measured with a Lex$\mathrm{O}_{2}$-Con (Lexington Instruments, Lexington, MA). Whole blood glucose, lactate, $\beta$-hydroxybutyrate, acetoacetate, and acetate were measured by standard enzymatic methods $(9,15)$. FFA were measured by the method of Ho (16).

Each assay was performed in triplicate for each sample for each vessel. Thus, the mean value for each day from a given vessel represented the mean of three assays on four samples for the same vessel, or the mean of 12 analyses. Interreplicate variations for analyses of oxygen and of glucose, lactate, and ketoacids ("substrates") were each less than $1 \%$. Intersample variability within a vessel on a given day for oxygen and substrate concentration was $7 \%$ (mean $\pm 2 \mathrm{SD}$ ). Overall estimate of the mean for the 12 analyses from a given vessel on a given day was within $1.5 \%$ for oxygen and substrate measurements. Arterial and venous concentrations of oxygen and substrates between draws of a set were not independent; the mean value of the AV difference was used as a single estimator in the statistical analyses between animals. Statistical analyses of the interanimal variation are given in the data tables. We observed no consistent pattern of variation of arterial or venous concentrations, or AV concentration differences, within sample sets on a given day, nor between days on animals studied twice.

Calculations. Substrate metabolic quotients were calculated by means of the following equation:

Substrate metabolic quotient

$$
=\frac{(\mathrm{AV}) \text { substrate }(\mathrm{mM}) \times \mathrm{K}}{(\mathrm{AV}) \text { oxygen }(\mathrm{mM})}
$$

where $\mathrm{K}=$ number of moles of $\mathrm{O}_{2}$ required for complete oxidation of $1 \mathrm{~mol}$ of substrate. $\mathrm{K}$ values were: acetate, 2; lactate, 3 ; acetoacetate, $4 ; \beta$-hydroxybutyrate, 4.5 ; and glucose, 6 . For FFA, we used a value of $K$ equal to 23 , based on a mean carbon chain length equal to 16 .

Statistics. Statistical analysis was performed using paired or unpaired $t$ tests as appropriate. Replicate determinations on samples from each animal were averaged to give a single value for each animal for each study day. Where a single animal was studied on 2 consecutive days, the mean values for each day were averaged to give a mean value for that animal. For statistical purposes, $n$ was taken to equal the numer of animals. Results are expressed as mean \pm SEM unless otherwise noted.

\section{RESULTS}

Table 1 presents the maternal weight, gestational age, total number of fetuses, and number of fetuses in the catheterized horn in 13 chronically catheterized preparations. All animals were between 40 and 49 days gestation at the time of study. There were at least two fetuses in each catheterized horn. Seven of the 13 animals were studied on 2 consecutive days; six were studied once.

Table 2 presents the mean arterial and uterine venous substrate and oxygen concentrations, and the uterine AV differences. There was a significant net flux of $\mathrm{O}_{2}$, glucose, and acetate from maternal blood to pregnant uterus to maternal blood $(p<0.01)$, and a significant net flux of lactate from pregnant uterus to maternal blood $(p<0.01)$. The mean AV difference of FFA was positive $(0.022 \mathrm{mM})$, but not significantly different from zero $(p$ $>0.05)$. The AV differences of $\beta$-hydroxybutyrate and acetoacetate were small (0.02 and $0.01 \mathrm{mM}$, respectively).

Metabolic quotients for glucose, lactate, ketoacids, and for fatty acids are presented in Table 2. Of the measured substrates, the uterine glucose/oxygen quotient was the largest, averaging $1.22 \pm 0.07$. Ketoacids demonstrated small AV differences and metabolic quotients, which were not statistically significant. The acetate/oxygen quotient was small but statistically significant, while the FFA uptake was not statistically significant.

Data demonstrating the necessity for collecting such uterine metabolic data under chronic steady state conditions are shown in Figure 2. Comparing acutely and chronically obtained values, uterine oxygen $\mathrm{AV}$ differences and coefficients of extraction were large in both acute and chronically catheterized animals, and were not significantly different. However, uterine glucose AV differences and uterine glucose extraction were both significantly greater in the acute compared to the chronic animals, with correspondingly greater glucose/oxygen metabolic quotients.

Table 1. Table of maternal wt, no. of fetuses, wt of placenta and fetuses in the entire uterus and in the horn that was catheterized and studied

\begin{tabular}{|c|c|c|c|c|c|c|c|c|c|c|}
\hline \multirow[b]{2}{*}{$\begin{array}{c}\text { Animal } \\
\text { no. }\end{array}$} & \multirow[b]{2}{*}{$\begin{array}{c}\text { Gestational } \\
\text { age }(y r)\end{array}$} & \multirow[b]{2}{*}{$\begin{array}{c}\text { Maternal } \\
\text { wt } \\
(\mathrm{g})\end{array}$} & \multicolumn{4}{|c|}{ Entire uterus } & \multicolumn{4}{|c|}{ Catheterized horn } \\
\hline & & & $\begin{array}{c}\text { Wt } \\
\text { of uterus } \\
(\mathrm{g})\end{array}$ & $\begin{array}{c}\text { No. } \\
\text { of } \\
\text { fetuses }\end{array}$ & $\begin{array}{c}\text { Total } \\
\text { fetal } \\
\text { wt }(\mathrm{g})\end{array}$ & $\begin{array}{c}\text { Total } \\
\text { placental } \\
\text { wt }(\mathrm{g})\end{array}$ & $\begin{array}{c}\text { Wt } \\
\text { of } \\
\text { horn }(\mathrm{g})\end{array}$ & $\begin{array}{c}\text { No. } \\
\text { of } \\
\text { fetuses }\end{array}$ & $\begin{array}{c}\text { Fetal } \\
\text { wt } \\
(\mathrm{g}) \\
\end{array}$ & $\begin{array}{c}\text { Placental } \\
\text { wt } \\
(\mathrm{g})\end{array}$ \\
\hline $81-58$ & 44 & 920 & 117.50 & 5 & 89.1 & 12.72 & 69.84 & 3 & 53.7 & 7.77 \\
\hline $81-61$ & 46 & 1125 & 90.45 & 3 & 67.5 & 10.73 & 88.43 & 3 & 67.5 & 10.73 \\
\hline $8 !-67$ & 45 & 760 & 55.84 & 2 & 37.8 & 5.91 & 54.33 & 2 & 37.8 & 5.91 \\
\hline $81-68$ & 49 & 970 & 146.98 & 4 & 112.8 & 12.56 & 108.77 & 3 & 83.1 & 9.35 \\
\hline $82-6$ & 44 & 950 & 77.82 & 3 & 55.6 & 9.17 & 76.21 & 3 & 55.6 & 9.17 \\
\hline $82-7$ & 46 & 1100 & 172.80 & 6 & 173.8 & 20.29 & 119.03 & 3 & 90.0 & 11.14 \\
\hline $82-10$ & 45 & 1140 & 103.30 & 5 & 163.0 & 16.60 & 81.30 & 3 & 73.7 & 9.40 \\
\hline $82-11$ & 46 & 1120 & 134.00 & 5 & 93.4 & 13.61 & 56.90 & 2 & 39.8 & 5.67 \\
\hline $82-30$ & 45 & 900 & 150.07 & 4 & 109.6 & 12.03 & 113.92 & 3 & 83.9 & 9.30 \\
\hline $82--36$ & 44 & 1025 & 83.38 & 3 & 59.6 & 9.09 & 81.59 & 3 & 59.6 & 9.09 \\
\hline $82-40$ & 48 & 1100 & 140.58 & 4 & 101.3 & 12.50 & 107.21 & 3 & 78.7 & 9.37 \\
\hline $82-43$ & 40 & 960 & 40.37 & 2 & 24.0 & 4.20 & 38.52 & 2 & 24.0 & 4.20 \\
\hline $82-44$ & 41 & 1070 & 145.32 & 6 & 95.5 & 15.26 & 50.25 & 2 & 30.9 & 5.28 \\
\hline
\end{tabular}


Table 2. Table of arterial and venous measurements of oxygen and substrates and substrate/O quotients fexpressed as mean

\begin{tabular}{|c|c|c|c|c|c|c|c|}
\hline Arterial & $6.38(0.23)$ & $5.26(0.21)$ & $1.06(0.09)$ & $0.13(0.02)$ & $0.13(0.03)$ & $0.42(0.04)$ & $325(77)$ \\
\hline Venous & $3.84(0.19)$ & $4.64(0.21)$ & $1.52(0.19)$ & $0.12(0.02)$ & $0.11(0.02)$ & $0.37(0.05)$ & $303(74)$ \\
\hline AV & $2.54(0.24)$ & $0.62(0.06)$ & $0.46(0.12)$ & $0.01(0.005)$ & $0.02(0102)$ & $0.05(0.01)$ & $22(16)$ \\
\hline $\begin{array}{l}n \\
\text { Quoticnt }\end{array}$ & 23 & $\begin{array}{c}13 \\
1.22(0.07)\end{array}$ & $\begin{array}{c}13 \\
-0.47(0.11) \\
(G+L) / O_{2}\end{array}$ & $\begin{array}{c}13 \\
0.01(0.01) \\
5(0.13)\end{array}$ & $\begin{array}{c}13 \\
0.03(0.02)\end{array}$ & $\begin{array}{c}13 \\
0.04(0.01)\end{array}$ & $\begin{array}{c}11 \\
0.24(0.21)\end{array}$ \\
\hline
\end{tabular}

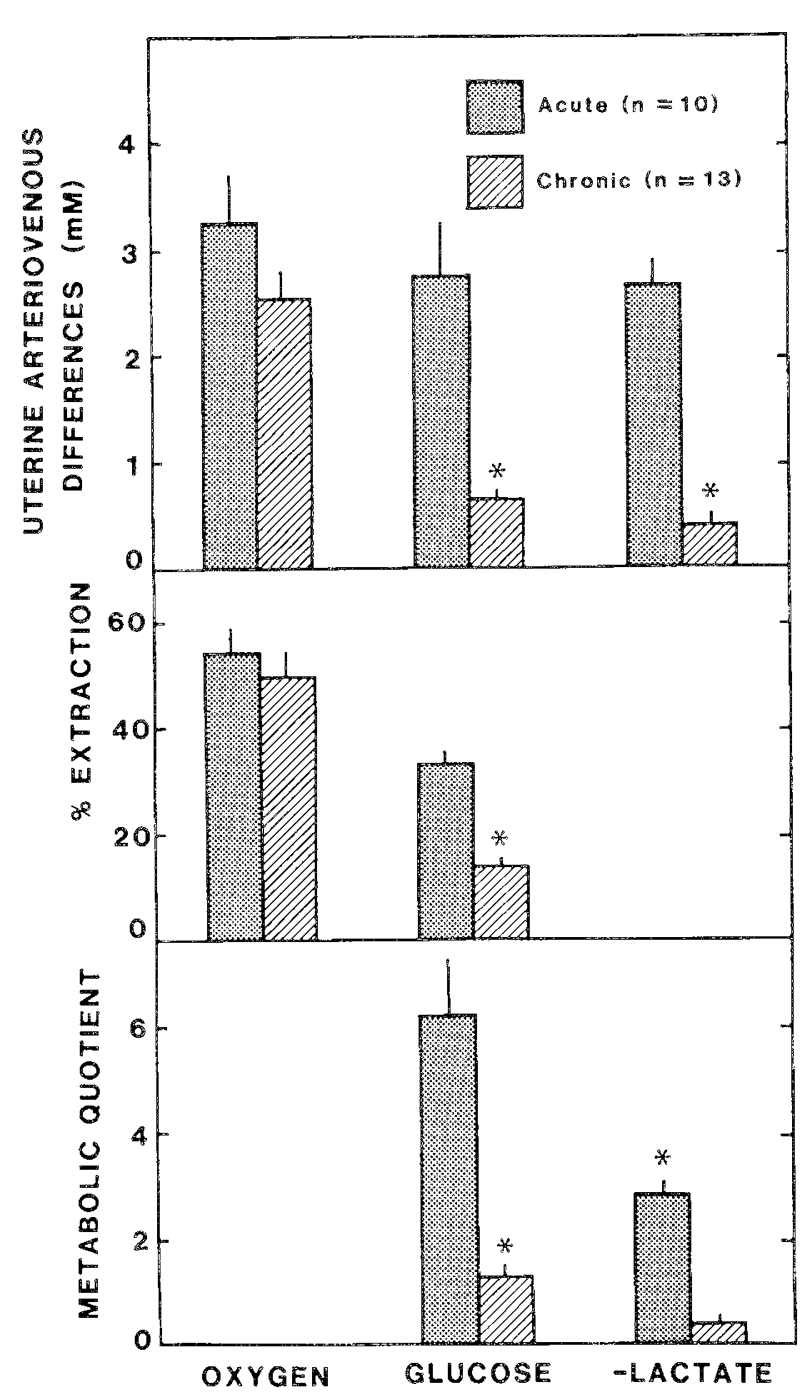

Fig. 2. Comparison of the AV differences of oxygen. glucose. and lactate in 10 acutely and 13 chronically catheterized guinea pigs. Coefficients of extraction of oxygen and glucose as well as glucose $/ \mathrm{O}_{2}$ and lactate $/ \mathrm{O}_{2}$ quotients are down. The asterisk indicates statistical significance between the acute and chronic experiments $(p<0.01)$.

Uterine lactate AV differences were negative in both groups, and were of significantly greater magnitude in the acutely sampled animals, with correspondingly larger negative lactate/oxygen quotients.

\section{DISCUSSION}

The present study describes metabolic quotients across the guinea pig uterus in the gestational age range $40-49$ days. This stage of gestation was chosen for two reasons. First, previous studies from this laboratory had shown both metabolic and circulatory changes occurring at approximately 50-55 days gestation in the guinea pig (9-12: Myers S. Sparks JW. Makowski
EL, Meschia G, Battaglia, personal communication). Thus, it seemed important to begin a study of uterine metabolism before this transition period. Second, the earlier time of 40-49 days was selected because at this stage the uterus is of only moderate size facilitating its surgical manipulation.

Acute animal data. We have previously demonstrated that anesthesia and surgery-induced stress lead to marked alterations in arterial substrate concentrations in the pregnant and nonpregnant guinea pig. These alterations in the pregnant animal include elevation of blood glucose and lactate concentrations compared to unstressed pregnant animals. If such changes were in proportion to changes in blood flow or oxygen substrate consumption, these acute studies could still give an accurate qualitative picture of metabolism at differing absolute rates of consumption. Studies of Myers et al. (personal communication) have documented under acute conditions disproportionately large reductions of uterine blood flow relative to cardiac output, and different quantitative reductions in flow with different anesthetic regimes. The present data demonstrate large oxygen extractions under chronic and acute conditions, with relatively little difference in oxygen extraction between the two groups. In contrast, the uterine extraction of glucose is small under chronic steady state conditions, but with much greater changes in glucose extraction and lactate production in the acute studies. Consequently, there are large alterations in substrate quotients under acute conditions compared to chronically prepared animals. Thus, in the pregnant guinea pig, data obtained acutely not only differ quantitatively compared to the chronic values, but qualitatively as well, yielding an incorrect description of unstressed uterine metabolism.

Uterine substrate/oxygen quotients. The present data, collected in unstressed animals, describe the metabolism of the uterus and its contents in terms of uterine AV differences and substrate/ oxygen quotients. AV differences document the direction of substrate flux to or from the uterus, while substrate/oxygen quotients quantify these fluxes relative to rates of $\mathrm{O}_{2}$ consumption; i.e. the substrate/oxygen quotient is the ratio of substrate uptake to oxygen uptake, expressed stoichiometrically, for complete oxidation of a particular substrate (equation 1). A major advantage of substrate/oxygen quotients is that these metabolic quotients permit quantitation of substrate metabolism without requiring measurement of uterine blood flow.

Several features need to be emphasized in using quotients to quantify uterine metabolism. First, quotients calculate a hypothetical stoichiometric amount of oxygen that would be required to completely oxidize a given substrate, but do not imply that the given substrate is indeed biologically completely oxidized. Growth and its accompanying tissue accretion of carbon and nitrogen (6) are examples of substrate uptake in excess of actual oxidation. Second, one may assign a sign convention, such that a positive substrate/oxygen quotient, expressed as a fraction of total oxygen consumption, calculates the maximal rate of net consumption of oxygen that would be required to oxidize the substrate completely. Conversely, a negative sign implies the maximal rate of net production of the substrate, which is equated to an oxygen "sparing" or "production." The net production of lactate by the gravid uterus is an example of such substrate production (4). Metabolism of glucose only as far as lactate "spares" as much oxygen by lactate production as would be "consumed" by glucose oxidation: no net oxygen is required for 
this reaction overall. Analogously, glucose consumption for lipogenesis is indeed an oxygen "producing" process. Third, the net production of a given substrate (e.g. lactate) need not imply that it is actually produced from carbon dioxide and water, but only that a stoichiometric amount of carbon dioxide and water could be consumed and oxygen produced, if such were to occur. In fact, from an energetic and enzymatic point of view, it is much more likely that lactate is produced from glucose or other organic substrates; the sign convention only derives from the above construct that the consumption of glucose and production of lactate are expressible in a common currency of energy, oxygen, and an array of products of complete oxidation.

From a quantitative point of view, bomb calorimetry presents an analogous type of measurement. Bomb calorimetric measurements of the caloric value of a substrate measure the calories produced by complete oxidation of that substrate; measurements of the bomb calorimetric value of a product represent the calories that would be required to produce the substrate product from the products of complete oxidation. Thermodynamics require that the caloric value of a given substance is intrinsic to the molecule, and not dependent on the route of synthesis. Thus, if the net quantitative balance of all nutrients entering and exiting an organism is completely known, then the sum of the net caloric production plus net caloric value of tissue accretion are also completely known and the net oxygen consumption can be calculated. This equivalence of calories and oxygen forms the basis for indirect calorimetry. For the conceptus, the uptake of substrates, oxygen, and calories may be expressed as the product of flow and AV difference (Fick principle); dividing these relationships of uptake by blood flow and total oxygen consumption yields the substrate/oxygen quotients.

For a nongrowing organ or organism producing calories oxidatively, there is no net retention of carbon and nitrogen. If each substrate is completely oxidized, then the moles of oxygen required can be calculated stoichiometrically from the net moles of substrate entering and exiting. If the entry and exit rates of all nutrients were known, then the total oxygen consumption could be calculated as the algebraic sum of oxygen required or produced for the complete oxidation or synthesis of each substrate. By definition, then, the total oxygen consumption of a nongrowing tissue equals the total oxygen required for complete oxidation of all net substrates, and the algebraic sum of all metabolic quotients for that tissue or organism must equal 1. In that case, the substrate/oxygen quotient of an individual substrate then represents the contribution of that substrate to the total organism's metabolism, expressed as a fraction of total oxygen consumption.

For a growing organism, the theoretical sum of all metabolic quotients is more complex. Again, assuming a completely determined and continuous net stream of nutrients entering the fetus, the oxygen required to completely oxidize this stream, $\mathrm{TO}_{2}$, can be determined. If the oxygen consumption, $\mathrm{VO}_{2}$, is known, then the oxygen equivalents that would be required for complete oxidation biologically of the substrates accreted in new tissue growth, $\mathrm{GO}_{2}$, can be estimated from the following relationship: (1) $\mathrm{TO}_{2}=\dot{\mathrm{VO}_{2}}+\dot{\mathrm{GO}_{2}}$. The fraction of $\mathrm{TO}_{2}$ actually consumed, $\mathrm{f}$, is given by (2) $\mathrm{f}=\mathrm{VO}_{2} / \mathrm{TO}_{2}$. For the nongrowing animal cited earlier, $\dot{\mathrm{GO}}_{2}=0$. Thus, in a nongrowing animal $\mathrm{TO}_{2}$ equals $\dot{\mathrm{VO}}_{2}$, f equals 1 , and the sum of metabolic quotients equals 1 . However, for a growing animal, $\dot{\mathrm{TO}} \mathrm{O}_{2}>\mathrm{VO}_{2}, \mathrm{f}<1$, and the actual $\mathrm{AV}$ difference of oxygen will be $f$ times that required for complete biologic oxidation of the entering nutrient stream. The sum of the metabolic quotients, calculated using $\mathrm{TO}_{2}$ as the denominator, will be 1 . If $\dot{\mathrm{VO}}_{2}$ is used as the denominator, the sum of quotients will be $>1$ and must equal $1 / \mathrm{f}$.

If the present experiments, the sum of measured quotients $=$ 0.83 . For a nongrowing animal, this value would imply that we had identified $83 \%$ of the substrate flux entering the conceptus. However, the products of conception are growing rapidly. Recent measurements of fetal carcass accretion by Sparks et al. (6) suggest that the caloric value of new tissue accretion in the guinea pig at 45 days is approximately $95 \mathrm{kcal} \cdot \mathrm{kg}$ conceptus ${ }^{-1} \cdot$ day $^{-1}$, of which approximately $40 \mathrm{kcal} \cdot \mathrm{kg}$ conceptus ${ }^{-1} \cdot \mathrm{day}^{-1}$ is required for protein accretion. Since these figures are based on bomb calorimetric measurement of tissue accretion rather than biologic oxidation, the biologically catabolizable fraction would be about 90 and $35 \mathrm{kcal} \cdot \mathrm{kg}$ conceptus ${ }^{-1} \cdot$ day $^{-1}$, respectively, carrying oxidation of amino acids only as far as urea. As noted by Kleiber (17), the oxygen required to catabolize protein, carbohydrate, or fat is relatively constant at $4.7 \mathrm{kcal} /$ liter $\mathrm{O}_{2}$. If the published values of acute measurements of oxygen consumption in the gravid uterus of the guinea pig (18) are converted to calories, this would correspond to approximately $55 \mathrm{kcal} \cdot \mathrm{kg}$ conceptus ${ }^{-1}$. $\mathrm{day}^{-1}$. Using these values, the value of $\mathrm{f}$ would equal $55 /(95+$ 55 ), or $1 / \mathrm{f}$ about 2.7 . Thus, the sum of quotients must equal approximately 2.7 under these conditions, with the result that the measured sum of quotients represents about a third of the actual nutrient stream entering the guinea pig fetus. It should be noted, however, that the actual oxygen consumption under unstressed conditions at this gestation may differ from the reported acute values, which would change the value of $f$.

Uptake and production of measured substrates. In interpreting the measured uterine AV differences and quotients, several additional points need to be considered.

First, the present data demonstrate significant lactate production by the conceptus. The metabolism of glucose to lactate results in a small amount of calorie and ATP production without associated oxygen consumption. This production is small, both on a caloric basis (glucose $=3.75 \mathrm{kcal} / \mathrm{g}$, lactate $=3.62 \mathrm{kcal} / \mathrm{g}$, difference $=0.13 \mathrm{kcal} / \mathrm{g}$, or $3.5 \%$ ) and on an ATP basis (glucose $=38 \mathrm{ATP} / 6$ carbons, lactate $=36 \mathrm{ATP} / 6$ carbons, difference $=$ 2 ATP or $5.3 \%$ ). For the present data, the glucose/oxygen quotient is decreased by $38 \%$ by the addition of the lactate/ oxygen quotient. The number of calories produced during production of lactate is small compared to the number of calories from glucose oxidation, and therefore, the addition of the lactate/ oxygen quotient to the glucose/oxygen quotient provides a reasonable estimate of net calories produced by the combined fates of glucose and lactate. The present sum of these quotients $(0.83)$ remains substantially below the estimated sum of quotients, further documenting that other substrates are major fuels for the conceptus.

The uteroplacental tissues of sheep and cattle produce lactate under aerobic conditions, which is delivered into both the uterine and umbilical circulations (2-5). While the lactate production by the sheep placenta is quite large, with a uterine lactate $/ \mathrm{O}_{2}$ quotient of approximately -0.1 (4), the lactate production rate relative to $\mathrm{O}_{2}$ consumption is even larger in the guinea pig, where the lactate/oxygen quotient is -0.4 . In both species, when the uterine glucose $/ \mathrm{O}_{2}$ quotient is adjusted for lactate production, the glucose not required for lactate production could account for approximately $75 \%$ of the oxygen consumption in both species $[$ (glucose + lactate $) / \mathrm{O}_{2}$ quotient $\left.=0.75\right]$. Recent studies in our laboratory have demonstrated a similar phenomenon in the rabbit, where the (glucose + lactate) $/ \mathrm{O}_{2}$ quotient is about 0.6 , the lactate $/ \mathrm{O}_{2}$ quotient being $-0.9(20)$. Thus, in the cow, sheep, guinea pig, and rabbit, net lactate efflux from the uterus has been demonstrated. It is important to note that this lactate production occurs concurrently with net oxygen consumption, and does not imply anaerobic metabolism (4).

Second, the FFA/oxygen quotient is not significantly different from 0 . We estimate that fetal growth at this gestation in the guinea pig requires aproximately $3.5 \mathrm{~g}$ fat $/ \mathrm{kg}$ fetal weight $/$ day. A coefficient of extraction of $10-15 \%$ would be sufficient for FFA to meet this rate of fat accretion. This is below the sensitivity of the methods used. The current data, therefore, do not preclude significant uptake of FFA, sufficient to account for the fetal fat accretion rate. Since the guinea pig placenta has been shown to be permeable to FFA $(20-22)$, the uptake of FFA by the uterus would not be surprising. This differs from the sheep, where the placenta is impermeable to FFA even when maternal FFA levels 
Table 3. Arterial concentrations, AV differences, and coefficients of extraction of acetate in guinea pig, sheep, and cow

\begin{tabular}{lccc} 
& Guinea pig* & Sheep $\dagger$ & Cow $\ddagger$ \\
\hline Arterial & & & \\
Concentration $(\mathrm{mM})$ & 0.42 & 1.53 & 0.90 \\
AV Difference $(\mathrm{mM})$ & 0.05 & 0.112 & 0.26 \\
Coefficient of extraction & 18.00 & 9.7 & 28.9 \\
A-V $\%$ & & &
\end{tabular}

* Data from the present study.

$\dagger$ Data from Char and Creasy (2).

$\ddagger$ Data from Comline and Silver (5).

are increased by fasting (23-25). In contrast, the perfused rabbit placenta has been shown to be permeable to FFA in experiments under acute conditions (26-28).

Third, the gravid guinea pig uterus clearly demonstrates a net acetate uptake despite the relatively low maternal arterial acetate concentrations. Table 3 presents the arterial concentrations of acetate in maternal arterial blood in the fed state for the sheep, guinea pig, and cow, which are $1.53,0.42$, and $0.90 \mathrm{mM}$, respectively. The coefficients of extraction for acetate in these three species are $18,9.7$, and $28.9 \%$, respectively. At this point in gestation, the acetate/oxygen quotient in the guinea pig is 0.04 . Acetate has been shown to be taken up by the umbilical circulation of the fetal lamb (2). Recently, Singh et al. (15) have shown a net uterine uptake of acetate in the sheep, where the acetate $/ \mathrm{O}_{2}$ quotient is 0.06 . For the cow, utilizing data derived from Comline and Silver (5), the acetate/oxygen quotient is approximately 0.04 .

Finally, a comment should be made about alternate approaches to catheterization of the venous circulation in the guinea pig. Previously, Egund and Carter (29) have pointed out that the right ovarian vein can be catheterized in a retrograde fashion through a catheter inserted in the jugular vein, passed through the right atrium into the inferior vena cava, and then into the ovarian vein. Peetes et al. (30) have used this approach for chronic catheterization of the uterine venous circulation in the guinea pig. The obvious advantage of this approach is that it does not require opening the abdomen and manipulating the uterus. However, with the modifications in anesthesia and in postoperative support outlined in this and previous papers from our laboratories, we have not found direct manipulation of the uterus to present a major problem in terms of fetal loss. The advantages of the direct operative approach used in the present report are that one can easily visualize the location of the catheter tip in the main confluence of the venous drainage, that the catheter is in the same direction as blood flow minimizing clotting problems, that one can determine at the time of surgery the number of fetuses in the catheterized horn, and that this method also does not expose personnel to radiation hazards inherent in the use of fluoroscopy.

\section{REFERENCES}

1. Battaglia FC, Meschia G 1978 Principal substrates of fetal metabolism. Physiol Rev 58:499-527
2. Char VC, Creasy RK 1976 Acetate as a metabolic substrate in the fetal lamb. Am J Physiol 230:357-361

3. Burd Ll, Jones MD, Simmons MA, Makowski EL, Meschia G, Battaglia FC 1975 Placental production and foetal utilization of lactate and pyruvate Nature 254:710-711

4. Sparks JW, Hay WW Jr, Meschia G, Battaglia FC 1982 Simultaneous measurements of lactate turnover rate and umbilical lactate uptake in the fetal lamb. J Clin Invest 70:179-192

5. Comline RS, Silver M 1976 Some aspects of foetal and uteroplacental metabolism in cows with indwelling umbilical and uterine vascular catheters. J Physiol (Lond) 260:571-586

6. Sparks JW, Girard JR, Callikan S, Battaglia FC 1985 Growth of the fetal guinea pig: physical and chemical characteristics. Am J Physiol 248:E132139

7. Sparks JW 1984 Human intrauterine growth and nutrient accretion. Semin Perinatol 8:74-93

8. Widdowson EM 1950 Chemical composition of newly born mammals. Nature $166: 626-628$

9. Sparks JW, Pegorier J-P, Girard J, Battaglia FC 1981 Substrate concentration changes during pregnancy in the guinea pig studied under unstressed steady state conditions. Pediatr Res 15:1340-1344

10. Myers SA, Sparks JW, Makowski EL, Meschia G, Battaglia FC 1982 The relationship between placental blood flow and placental and fetal size in the guinea pig. Am J Physiol 243:H404-H409

11. Peeters LL, Sparks JW, Grutters G, Girard J, Battaglia FC 1982 Uteroplacental blood flow during pregnancy in chronically catheterized guinea pigs. Pediatr Res 16:716-720

12. Gilbert M, Sparks JW, Girard J, Battaglia FC 1982 Glucose turnover rate during pregnancy in the conscious guinea pig. Pediatr Res 16:310-313

13. Draper RL 1920 The prenatal growth of the guinea pig. Anat Rec 18:367-392

14. Ibsen HL 1928 Prenatal growth in guinea pigs with special reference to environmental factors affecting weight at birth. J Exp Zool 51:51-91

15. Singh S, Sparks JW, Hay WW Jr, Battaglia FC, Meschia G 1984 Comparison of fetal and maternal hind limb metabolic quotients in sheep. Am J Obstet Gynecol 149:441-449

16. Ho RJ 1970 Radiochemical assay of long chain fatty acids using ${ }^{63} \mathrm{Ni}$ as tracer. Anal Biochem 36:105-113

17. Kleiber M 1975 The Fire of Life: An Introduction to Animal Energetics. Robert E Kreiger Publishing Co, Huntington, NY, pp 111-130

18. Moll W, Kunzel W, Ross HG 1970 Gas exchange of the pregnant uterus of anaesthetized and unanaesthetized guinea pigs. Respir Physiol 8:303-310

19. Johnson RL, Block S, Gilbert M, Battaglia FC, Meschia G 1983 Uterine oxygen and substrate uptakes in the pregnant rabbit under chronic steady state conditions. Soc Gynecol Invest 309:179-179 (abstr)

20. Herschfield MS, Nemeth AM 1968 Placental transport of free palmitic and linoleic acids in the guinea pig. $J$ Lipid Res 9:460-468

21. Kayden HJ, Dancis JD, Money WL 1969 Transfer of lipids across the guinea pig placenta. Am J Obstet Gynecol 104:564-572

22. Satomura K, Soderhjelm L 1962 Deposition of fatty acids in the newborn in relation to the diet of pregnant guinea pigs: a preliminary report. Tex Rep Biol Med 20:671-679

23. Elphick MC, Hull D, Pipkin FB 1979 The transfer of fatty acids across the placenta. J Dev Physiol 1:31-45

24. James E, Meschia G, Battaglia FC 1971 A-V differences of free fatty acids and glycerol in the ovine umbilical circulation. Proc Soc Exp Biol Med 138:823826

25. Schreiner RL, Burd LI, Jones MD, Lemon JA, Sheldon RE, Simmons MA, Battaglia FC, Meschia G 1977 Fetal metabolism in fasting sheep. In: Longo L, Reneau D (eds) Fetal and Newborn Cardiovascular Physiology, Vol II. Rowen, New York pp 197-222

26. Edson JL, Hudson DG, Hall D 1975 Evidence for increased fatty acid transfer across the placenta during a maternal fast in rabbits. Biol Neonate 27:50-5.

27. Elphick MC, Hudson DG, Hull D 1975 Transfer of fatty acids across the rabbit placenta. J Physiol (Lond) 252:29-42

28. Van Duyne GM, Havel RJ, Felts JM 1962 Placental transfer of palmitic acid1-C ${ }^{14}$ in rabbits. Am J Obstet Gynecol 84:1069-1074

29. Egund H, Carter AM 1974 Uterine and placental circulation in the guinea pig: an angiographic study. J Reprod Fertil 40:401-410

30. Peeters LL, Walle AF vd, Grutters GG 1984 Technique for chronic blood sampling from the ovarian vein in the pregnant guinea pig. Pediatr Res 18:1172-1175 